\title{
Differential gene expression in skeletal organic matrix proteins of scleractinian corals associated with mixed aragonite/calcite skeletons under low $\mathrm{mMg} / \mathrm{Ca}$ conditions
}

\author{
Ikuko Yuyama ${ }^{1}$, Tomihiko Higuchi ${ }^{\text {Corresp. } 2}$ \\ ${ }^{1}$ Faculty of Life and Environmental Sciences, University of Tsukuba, Tsukuba, Ibaraki, Japan \\ 2 Atmosphere and Ocean Research Institute, The University of Tokyo, Kashiwa, Chiba, Japan \\ Corresponding Author: Tomihiko Higuchi \\ Email address: thiguchi@aori.u-tokyo.ac.jp
}

Although coral skeletons generally comprise aragonite crystals, changes in the molar $\mathrm{Mg} / \mathrm{Ca}$ ratio $(\mathrm{mMg} / \mathrm{Ca})$ in seawater result in the incorporation of calcite crystals. The mechanism of formation of aragonite and calcite crystals in skeletons of the scleractinian coral Acropora tenuis was therefore investigated by RNA-seq analysis, using early growth stage calcite $(\mathrm{mMg} / \mathrm{Ca}=0.5)$ and aragonite $(\mathrm{mMg} / \mathrm{Ca}=5.2)$-based corals. As a result, 1,287 genes were up-regulated and 748 down-regulated in calcite-based corals. In particular, sixty eight skeletogenesis-related genes, such as ectin, galaxin, and skeletal aspartic acidrich protein, were detected as up-regulated, and six genes, such as uncharacterized skeletal organic matrix protein 5, down-regulated, in low-Mg/Ca conditions. Since the number of down-regulated genes associated with the skeletal organic matrix of aragonite skeletons was much lower than that of up-regulated genes, it is thought that corals actively initiate construction of an aragonite skeleton by the skeletal organic matrix in low$\mathrm{Mg} / \mathrm{Ca}$ conditions. In addition, different types of skeletal organic matrix proteins, extracellular matrix proteins and calcium ion binding proteins appeared to change their expression in both calcite-formed and normal corals, suggesting that the composition of these proteins could be a key factor in the selective formation of aragonite or calcite $\mathrm{CaCO}_{3}$. 
2 Differential gene expression in skeletal organic matrix

3 proteins of scleractinian corals associated with mixed

4 aragonite/calcite skeletons under low $\mathbf{m M g} / \mathbf{C a}$

5 conditions

6

7 Ikuko Yuyama ${ }^{1}$, Tomihiko Higuchi ${ }^{2}$

8

$9 \quad{ }^{1}$ Faculty of Life and Environmental Sciences, University of Tsukuba, Tsukuba city, Ibaraki, 10 Japan

$11{ }^{2}$ Atmosphere and Ocean Research Institute, The University of Tokyo, Kashiwa city, Chiba, 12 Japan

14 Corresponding Author:

15 Tomihiko Higuchi ${ }^{2}$

16 Atmosphere and Ocean Research Institute, The University of Tokyo, 5-1-5 Kashiwanoha,

17 Kashiwa, Chiba, 277-8564, Japan

18 Email address: thiguchi@aori.u-tokyo.ac.jp 


\section{Abstract}

22 Although coral skeletons generally comprise aragonite crystals, changes in the molar $\mathrm{Mg} / \mathrm{Ca}$ 23 ratio $(\mathrm{mMg} / \mathrm{Ca})$ in seawater result in the incorporation of calcite crystals. The mechanism of 24 formation of aragonite and calcite crystals in skeletons of the scleractinian coral Acropora tenuis 25 was therefore investigated by RNA-seq analysis, using early growth stage calcite $(m \mathrm{Mg} / \mathrm{Ca}=0.5)$ 26 and aragonite $(m \mathrm{Mg} / \mathrm{Ca}=5.2)$-based corals. As a result, 1,287 genes were up-regulated and 748 27 down-regulated in calcite-based corals. In particular, sixty eight skeletogenesis-related genes, 28 such as ectin, galaxin, and skeletal aspartic acid-rich protein, were detected as up-regulated, and 29 six genes, such as uncharacterized skeletal organic matrix protein 5, down-regulated, in low$30 \mathrm{Mg} / \mathrm{Ca}$ conditions. Since the number of down-regulated genes associated with the skeletal organic matrix of aragonite skeletons was much lower than that of up-regulated genes, it is thought that corals actively initiate construction of an aragonite skeleton by the skeletal organic matrix in low- $\mathrm{Mg} / \mathrm{Ca}$ conditions. In addition, different types of skeletal organic matrix proteins, extracellular matrix proteins and calcium ion binding proteins appeared to change their expression in both calcite-formed and normal corals, suggesting that the composition of these proteins could be a key factor in the selective formation of aragonite or calcite $\mathrm{CaCO}_{3}$.

\section{Introduction}

Calcium carbonate deposition by scleractinian corals is directly linked to the development of coral reefs, providing the structural basis of high species diversity coral reef ecosystems. Of the two major crystal types of calcium carbonate produced by marine calcifying organisms, aragonite is common in modern scleractinian corals, although calcite occurs in precious corals (genus Corallium) as well as foraminifera (Porter 2007; 2010). There is great diversity in calcite versus aragonite spicules in sponges (Uriz 2006), and calcite versus aragonite versus a mix in mollusk (Belcher et al. 1996). Although each crystal type is specifically determined by each marine organism, environmental conditions, such as molar $\mathrm{Mg} / \mathrm{Ca}$ ratio $(\mathrm{mMg} / \mathrm{Ca})$ and seawater temperature, can also influence crystal type selectivity (Ries et al. 2006; Higuchi et al. 2017). Fossil records indicate that $\mathrm{Mg}$ concentrations, resulting from fluctuations in past seawater $m \mathrm{Mg} / \mathrm{Ca}$ ratios, have impacted greatly on the selective nucleation of aragonite/calcite crystals 
52 (Ries 2010). For example, high $m \mathrm{Mg} / \mathrm{Ca}$ is favorable for precipitating aragonite, and low $53 \mathrm{mMg} / \mathrm{Ca}$, for precipitating calcite (Balthasar and Cusack 2015). During the Cretaceous period, 54 characterized by low $m \mathrm{Mg} / \mathrm{Ca}$, scleractinian corals (with aragonite skeletons) have been poorly 55 reported form the fossil record whereas rudist bivalves, which produced calcite, were the main 56 reef builder (Stanley and Hardie 1998; Stanley 2003; Janiszewska et al. 2017).

57 Although the mechanisms by which calcite versus aragonite crystals are selectively produced 58 by each marine organism are still incompletely understood, biogenic calcium carbonate is known to contain organic matrices that are key components for skeletal growth and determination of carbonate polymorphism (Rahman and Oomori 2009; Goffredo et al. 2011). Changing crystal formation may be accompanied by differing nucleation properties of specific proteins; for example, polyanionic proteins extracted from shells control the crystal phase by switching sequentially between aragonite and calcite (Belcher et al. 1996). In corals, galaxin, coral acidrich proteins (CARPs), and skeletal acidic Asp-rich proteins (SAARPs) have been identified as skeletal organic matrix proteins (Drake et al. 2013; Ramos-Silva et al. 2013; Fukuda et al. 2003). In addition, recent large scale transcriptome and proteomics analyses of corals during initial skeletal formation revealed that the expression of these organic matrix and extracellular matrixlike proteins was prominent in the initial skeleton-building process (Mass et al. 2016; Takeuchi et al. 2016). The accumulation of such molecular level information promises future discoveries of new molecular mechanisms underlying the crystallization and skeletogenesis of corals.

Previous studies, which demonstrated that juvenile corals produced calcite skeletons when incubated in low-Mg conditions, whereas corals produced $100 \%$ aragonite skeletons in ambient conditions (Higuchi et al. 2014), helped clarify the skeletal formation process in corals, as well as the aragonite/calcite switching mechanisms. The present study was undertaken to clarify the mechanism of calcite formation in scleractinian corals, by comparing gene differential expression profiles between calcite-formed and normal aragonite-formed corals.

\section{Materials \& Methods}

\section{Coral specimens}


83

84 Larval cultures of the scleractinian coral Acropora tenuis were obtained from the Akajima

85 Marine Science Laboratory (Okinawa, Japan). Several days after spawning, metamorphosis was

86 induced by exposure of the larvae (in $55 \mathrm{~mm}$ diameter plastic containers) to $2 \mu \mathrm{M} \mathrm{Hym}-248$, as

87 described in Iwao et al. (2002). Symbiodinium strains CCMP2556 (clade D), obtained from the

88 Bigelow Laboratory for Ocean Sciences (West Boothbay Harbor, ME, USA;

89 https://ccmp.bigelow.org/), were introduced to A. tenuis primary polyps, as described in Yuyama 90 and Higuchi (2014). Juvenile coral polyps were incubated with two different molar $\mathrm{Mg} / \mathrm{Ca}$ ratios $91(\mathrm{mMg} / \mathrm{Ca} 5.2$ and 0.5$)$, each in both natural and manipulated seawater, at $25^{\circ} \mathrm{C}$ in

92 thermostatically-controlled incubators (THS030PA; Advantec) with LED lighting (100 $\mu \mathrm{mol} \mathrm{m} \mathrm{m}^{-2}$ $93 \mathrm{~s}^{-1}, 12 \mathrm{~h}: 12 \mathrm{~h}$ light:dark cycle). Seawater was changed every $2-3$ days. Manipulated seawater $94(\mathrm{mMg} / \mathrm{Ca}=0.5)$ was prepared by mixing filtered (pore size: $0.22 \mu \mathrm{m})$ natural seawater and $\mathrm{Mg}$ 95 free artificial seawater, as described in Higuchi et al. (2017). Four containers (each containing 96 approximately 50 polyps) were prepared, two for natural seawater $(m \mathrm{Mg} / \mathrm{Ca}=5.2)$ and the other 97 two for low-Mg seawater $(m \mathrm{Mg} / \mathrm{Ca}=0.5)$. After incubation for two months, several polyps from 98 each container were treated with $\mathrm{NaClO}$ to remove tissue prior to confirmation of their crystal 99 structure, the remaining polyps being fixed in RNAlater (Ambion, Austin, TX, USA) for 100 transcriptome analysis.

101

\section{Determination of Crystal Structure}

103

104 Coral skeleton crystal structures were determined by X-ray diffraction (XRD). 5 juvenile 105 skeletons produced in $m \mathrm{Mg} / \mathrm{Ca} 5.2$ treatment and 20 juvenile skeletons produced in $m \mathrm{Mg} / \mathrm{Ca} 0.5$ treatment were analyzed by X-ray diffractometer (SmartLab, Rigaku, Japan) with a low background silicon holder. Calcite intensity was much stronger than that of aragonite, the specific peak of the latter $(<10 \mathrm{wt} \%$ ) being almost equivalent to the background (as described in Higuchi et al. 2017). The presence of aragonite was therefore confirmed by Meigen's stain at 85 ${ }^{\circ} \mathrm{C}$ for $10 \mathrm{~min}$ (Hang et al., 2014).

\section{Transcriptome analysis}


114 Two replicates of RNA-seq analysis derived from two containers were prepared for each

115 seawater condition $(\mathrm{mMg} / \mathrm{Ca}$ ratio 5.2 and 0.5$)$. Each replicate, including 30-40 polyps, was

116 homogenized (Ultra-Turrax T8 Homogenizer, Ika-Werke, Germany), and total RNA isolated

117 using a PureLink RNA Mini kit (Life Technologies corporation, Carlsbad, CA) and treated with

118 DNase I (TAKARA, Ohtsu, Japan) to digest genomic DNA. mRNA was then isolated using the

119 NEBNext Poly(A) mRNA Magnetic Isolation Module (NEB, Ipswich, MA), and cDNA libraries

120 prepared using the NEBNext mRNA Library Prep Master Mix Set for Illumina (NEB). Paired-

121 end sequencing of 100 bp was performed by Macrogen Japan (Kyoto, Japan), using a HiSeq

1222000 sequencer (Illumina, San Diego, CA). Short reads were first pre-processed, trimming bases

123 with a Phred quality score below $\mathrm{Qv}=20$ from the 5' and 3' ends of each read, and retaining

124 reads $\geq 25 \mathrm{bp}$. Reads with $30 \%$ of bases having Qv $\leq 15$ were filtered out using the DDBJ Read

125 Annotation Pipeline (same as Yuyama et al. 2018). Sequence data were deposited in the

126 DDBJ/EMBL/GenBank databases under accession number DRA007943. The reads were

127 assembled using Trinity v.2.1.1. Transdecoder v.2.1.0 and CD-HIT v. 4.6.1 were used to predict

128 Open reading frames, and filter for redundancy and uniqueness. To isolate coral-derived

129 transcripts, resulting contigs were aligned to coral transcriptome data [including an $A$. digitifera

130 genome (Shinzato et al. 2011), and non-symbiotic A. hyacinsus and A. tenuis transcriptomes

131 from (http://www.bio.utexas.edu/research/matz_lab/matzlab/Data.html) and the Center for

132 Information Biology, National Institute of Genetics (DDBJ accession number of

133 IADL01000001-IADL01108246, Yuyama et al. 2018) using BLASTN (e-value cutoffs < 1e-

134 15)]. Subsequently, trimmed reads were mapped to coral contigs using Bowtie2, and each gene

135 expression level counted using eXpress v.1.5.1. iDEGES/edgeRmethod (Sun et al. 2013) was

136 performed to detect differentially expressed genes $(\mathrm{FDR}<0.05)$ between normal aragonite coral

137 (grown in natural seawater) and calcite corals (grown in low $\mathrm{Mg} / \mathrm{Ca}$ seawater). Differentially

138 expressed transcripts were annotated with BLASTX against the (public) UniProtKB/Swiss-Prot

139 protein database (e-value cutoffs $<1 \mathrm{e}-6$ ). Gene ontology enrichment analysis was performed

140 using DAVID (https://david.ncifcrf.gov/) (Huang et al. 2009) to predict significant biological

141 processes affected by seawater $\mathrm{Mg} / \mathrm{Ca}$ ratios. Swiss-Prot annotation results of all coral contigs

142 identified here were used to provide a background set for GO enrichment analysis,.

143 


\section{Results}

\section{Skeletal mineralogy}

$148 \mathrm{XRD}$ revealed that the coral skeleton produced in $m \mathrm{Mg} / \mathrm{Ca}=5.2 \mathrm{had}$ an aragonite specific pattern, 149 whereas that produced in $m \mathrm{Mg} / \mathrm{Ca}=0.5 \mathrm{had}$ a calcite specific pattern (Fig. 1). Meigen's stain also 150 indicated a small portion of aragonite in the latter. Accordingly, the two coral types were 151 prepared for RNA-seq, one producing a mixed calcite/aragonite ( $>90 \%$ of calcite and $<10 \%$ 152 aragonite) skeleton in a low-Mg environment, and the second producing a normal aragonite 153 skeleton in natural conditions (hereafter, the former is described as 'calcite coral' and the latter 154 as 'aragonite coral').

\section{Differentially expressed genes corresponding to a $\mathrm{Mg} / \mathrm{Ca}$ ratio change}

157

158

159

160

161

162

163

164

165

166

167

168

169

170

171

172

173

The RNA-seq analysis resulted in an average of 36.6 million 100-base long reads obtained from each sample. A total of 40,776 coral-derived contigs (mean length 917 bp, N50 length 1,266 bp) were generated by de-novo assembles of all reads and blastn alignment to existing coral data. All reads were then mapped to the 40,776 contigs to detect the expression levels of each contig. Mapping reads were counted as FPKM (Fragments per kilobase of exon per million reads mapped). Comparison of normalized FPKM values between control and low-mg conditions detected 2,035 differentially expressed genes (FDR < 0.05), 1,287 being up-regulated and 748 down-regulated in calcite coral. A BLASTX search (e-value, 1e-6) of these differentially expressed contigs against the UniProtKB/Swiss-Prot database for gene annotation found 1,143 contigs assigned to known protein sequences, the 50 most significantly up-regulated and downregulated contigs in calcite coral being shown in Table S1. Putative skeletal organic matrix proteins (galaxin, skeletal aspartic acid -rich protein and uncharacterized skeletal organic matrix protein), extracellular matrix proteins (collagen alpha), and some toxins (toxin AvTX-60A and toxin PsTX-60A) were identified as the most up-regulated genes (Table S1a), with extracellular matrix proteins (dematopontin, tenascin- $\mathrm{R}$ and hemicentin-2) and cytochrome $\mathrm{P} 450$ being the most down-regulated (Table S1b).

\section{Gene ontology enrichment analysis}


175 The differentially expressed genes between low-Mg conditions $(m \mathrm{Mg} / \mathrm{Ca}=0.5)$ and control

176 conditions $(\mathrm{mMg} / \mathrm{Ca}=5.2)$ were sorted into enrichment categories, according to $\mathrm{GO}$ enrichment

177 analysis. Significantly enriched gene ontology characterizing the two conditions is described in

178 Fig. 2, with supplemental Figs. S1-S10 showing the expression levels and annotation information

179 of contigs contained in each category. The GO analysis indicated that some signaling pathways,

180 for example, Wnt signaling pathway (GO:0016055) and JAK-STAT cascade (GO:0007259),

181 were up-regulated in calcite coral. Moreover, GO terms involved in some metabolic systems,

182 including tetrapyrrole (GO:0046906), secondary alcohol metabolic process (GO:1902652), and

183 extracellular matrix (GO:0031012), were also enriched in up-regulated genes, whereas GO terms

184 involved in stress response [response to oxidative stress (GO:0006979) and necrotic cell death

185 (GO:0070265)] were enriched in down-regulated genes. Fig. 2 also showed that GO related to

186 calcium ion binding (GO:0005509) and extracellular matrix (GO:0031012) were enriched in

187 both situations, especially in up-regulated genes in calcite coral compared with aragonite coral.

190 Discussion

191 Although scleractinian corals usually produce aragonite skeletons, they can produce calcite-

192

193

194

195

196

197

198

199

200

201

202

203

204

205 aragonite mixed skeletons (referred as calcite coral) in low- $\mathrm{Mg} / \mathrm{Ca}$ conditions (Ries et al. 2006; Higuchi et al. 2017). To understand the formation mechanisms of each crystal type in corals, the gene differential expression profile was compared between calcite and aragonite corals. In this study, genes involved in carbonate chemistry of the calcifying fluid, such as Ca ATPase (Zoccola et al. 2004) and bicarbonate anion transporter (Zoccola et al. 2015), were in neither the top 50 up- or down-regulated genes, nor the full list of DE genes. Thus, we propose that change in $m \mathrm{Mg} / \mathrm{Ca}$ in seawater did not impact the carbonate chemistry of the calcifying fluid, although the calcification rate decreased with low Mg/Ca seawater (Higuchi et al. 2014; Higuchi et al. 2017). Our transcriptome data for gene subsets related to skeletogenesis is provided in the supplemental Table S2 and S3. These Tables show that upregulation and downregulation of extracellular matrix, acidic protein genes implying the change in expression of these genes contribute to the formation of calcite or aragonite crystal polymorph. Sixty eight potential skeletogenesis-related genes, i.e., those whose annotation names match skeletal proteins found in Ramos-Silva et al. (2013), were upregulated in calcite corals (low $m \mathrm{Mg} / \mathrm{Ca}$ condition) (Fig. 3). For example, the 
206 homologs of galaxin, skeletal aspartic acid-rich protein and uncharacterized skeletal organic 207 matrix protein 2 all showed high expression in calcite corals (Table S2). Moreover, other 208 putative skeletogenesis-related genes, including gene encoding thrombospondin (calcium ion 209 binding protein) (Fig. S5) and toxins, which have been reported as highly expressed genes in the 210 initial steps of coral skeleton formation (Mass et al. 2016, Takeuchi et al. 2016), were detected.

211 Some toxin types (Milepora cytotoxin, toxin AvTX-60A, and toxin PsTX-60A) were markedly 212 elevated (Table S1a), whereas cytotoxin-1 was down-regulated about 90\% in calcite coral. 213 Although the role of toxins in coral skeletogenesis is not yet known, AvTX-60A is characterized 214 by cysteine rich repeats (Bellomio et al. 2009), being similar to the coral skeletal matrix protein 215 galaxin (Reyes-Bermudez et al. 2009; Fukuda et al. 2003). In addition, Ramos-Silva et al. 2013 216 reported a further toxin (cephalotoxin-like protein) from the skeleton of $A$. millepora. These 217 findings suggest that some toxins are also included in the coral skeleton organic matrix, and may 218 contribute to skeleton formation. GO enrichment analysis indicated many gene types involved in 219 extracellular matrix and collagen metabolic processes, their expression in calcite corals being 220 221 222 223 224 225 increased by calcium ion binding (Fig. 2). Compared with inorganically precipitated $\mathrm{CaCO}_{3}$ crystals (aragonite/calcite mixed crystals) in similar low Mg conditions, more aragonite forms in coral skeletons (Balthasar and Cusack 2015; Higuchi et al. 2017), suggesting that the latter are biologically produced by the expression of genes involved in normal scleractinian coral skeletal formation (i.e. aragonite $\mathrm{CaCO}_{3}$ ), resulting in the formation of more aragonite crystals even in low $m \mathrm{Mg} / \mathrm{Ca}$ conditions.

It is noteworthy that many genes involved in signal transduction were up-regulated in calcite corals (Fig. 2). For example, the Wnt signaling pathway and JAK-STAT cascade were both 228 identified as up-regulated genes. It has already been reported that the former and TGF- $\beta /$ BMP play roles in the biomineralization of corals (Gutner-Hoch et al. 2017; Zoccola et al. 2009), in addition to being involved in collagen secretion in human cells ( $\mathrm{Li}$ et al. 2016). In the present results, the Wnt signaling pathway showed similar expression patterns to the collagen metabolic process, suggesting that it may be involved in coral skeletogenesis through the secretion of 233 collagen. Collagen related protein has also been reported from the skeletal organic matrix of the coral Stylophora (Drake et al. 2013). In pearl oyster shells, aspein is an acidic protein which contains a high proportion of aspartic acid (60.4\%) in the main body of the protein, which is 
237 rich protein were up-regulated as skeletal organic matrix (Table S2). Thus, aspartic acid rich 238 protein may function in calcite formation in scleractinian corals under low $m \mathrm{Mg} / \mathrm{Ca}$.

239 Down-regulated genes detected in calcite corals during the present study, included some 240 isoforms of dematopontin (Table 1b) [previously identified as a shell organic matrix protein 241 (Sarashina et al. 2006; Jiao et al. 2012)]. Similarly, the extracellular matrix proteins hemicentin-2 242 and tenascin-R both had markedly decreased expression (Fig. S3 and S5). Only six genes related 243 to skeletal organic matrix were down-regulated in the calcite corals (Table S3), whereas many 244 genes coding organic matrix proteins identified from aragonitic corals were up-regulated (despite 245 the small amount of aragonite formed in the calcite corals). It seems likely that even in low $246 \mathrm{Mg} / \mathrm{Ca}$ seawater (unfavorable conditions for aragonite production), corals actively promote the 247 skeletal organic matrix to construct an aragonite skeleton more than the calcite alternative.

248 Down-regulated genes (uncharacterized skeletal organic matrix protein 5 and zona pellucida (Zp) 249 domain-containing protein), also found on the up-regulated gene list (Table S2), may be involved 250 in basic coral skeleton formation, regardless of aragonite or calcite. Present data also suggested 251 that different types of organic matrix proteins, including both skeletal and extracellular, and 252 calcium ion binding proteins were highly expressed in aragonite and calcite corals. It is thought 253 that such variations in expression of organic matrix genes between calcite and aragonite corals 254 may be related to major coral skeleton crystal types.

255 Stress reactions due to $\mathrm{Mg}$ deficiency also occur in calcite corals under low-Mg conditions. 256 Cytochrome P450, known to decrease in expression in Mg-deficient rats (Becking and Morrison 257 1970), was also downregulated in calcite corals, possibly due to Mg-deficiency. In addition, 258 enriched GO terms associated with "response to DNA-dependent DNA replication 259 (GO:0006261)" in down-regulated genes in low-Mg (Fig. 2), appear to indicate the influence of $260 \mathrm{Mg}$-deficiency, $\mathrm{Mg}$ ions being an essential co-factor for almost all enzymatic system activity 261 acting on DNA processing (Hartwig 2001). The present results also suggested that $\mathrm{Mg}-$ 262 deficiency influenced other ion homeostasis; genes related to potassium ion transport 263 (GO:0006813) and copper ion binding (GO:0005507) were up-regulated (Fig. 2), and some heme 264 binding proteins (ferritin and heme-binding protein2) were down-regulated (Fig. 2 and Fig. S6). 265 In particular, a decrease in heme-binding protein may be related to or result from a side effect of 266 calcite formation in corals, since iron ions inhibit the growth of calcite (Katz et al. 1993). 


\section{Conclusions}

270 The present study demonstrated that a large number of genes related to aragonite skeletogenesis 271 in corals were up-regulated under low-Mg conditions. In addition, different types of organic 272 matrix proteins, extracellular matrix proteins and calcium ion binding proteins were expressed in 273 calcite and aragonite corals, suggesting that such proteins might also contribute to coral crystal 274 formation. To clarify whether or not the above gene differential expressions indeed contribute to 275 the formation of calcite or aragonite skeletons, further studies, such as proteome analysis of the 276 skeletal organic matrix in calcite-formed corals, are necessary. Notwithstanding, the present 277 study resulted in a list of candidate molecules involved in biogenetic control of calcite and 278 aragonite formation in coral skeletons, and may also contribute to clarification of the 279 mechanisms of calcium carbonate skeleton formation in various organisms.

280

281

282

283

284

285

286

287

288

289

290

291

292

293

294

295

296

297

298

\section{Acknowledgements}

We are grateful to members of the Akajima Marine Science Laboratory, especially Mr. Kenji Iwao, for provision of Acropora tenuis larvae, and also appreciate the members of the Laboratory for DNA data analysis in NIG. RNA-seq data analysis was partially performed on the NIG supercomputer at the National Institute of Genetics. We also appreciate Dr. Graham Hardy for English language editing.

\section{References}

Balthasar U, Cusack M. 2015. Aragonite-calcite seas-Quantifying the gray area. Geology 43: 99-102

Becking GC, Morrison AB. 1970. Role of dietary magnesium in the metabolism of drugs by NADPH-dependent rat liver microsomal enzymes. Biochem Pharmacol 19: 2639-2344. Belcher AM, Wu XH, Christensen RJ, Hansma PK, Stucky GD, Morse DE. 1996. Control of crystal phase switching and orientation by soluble mollusc-shell proteins. Nature 381:56-58. Bellomio A, Morante K, Barlic A, Gutiérrez-Aguirre I, Viguera AR, González-Mañas JM. 2009. Purification, cloning and characterization of fragaceatoxin $\mathrm{C}$, a novel actinoporin from the sea anemone Actinia fragacea. Toxicon 54: 869-880. 
299

300

301

302

303

304

305

306

307

308

309

310

311

312

313

314

315

316

317

318

319

320

321

322

323

324

325

326

327

328

329

330

331

332

333

334

335

336

337

Drake JL, Mass T, Haramaty L, Zelzion E, Bhattacharya D, Falkowski PG. 2013. Proteomic analysis of skeletal organic matrix from the stony coral, Stylophora pistillata. Proc Natl Acad Sci 110: 3788-3793.

Fukuda I, Ooki S, Fujita T, Murayama E, Nagasawa H, Isa Y, Watanabe T. 2003.

Molecularcloning of a cDNA encoding a soluble protein in the coral exoskeleton. Biochem Biophys Res Commun 304: 11-17.

Goffredo S, Vergni P, Reggi M, Caroselli E, Sparla F, Levy O, Dubinsky Z, Falini G. 2011. The skeletal organic matrix from Mediterranean coral Balanophyllia europaea influences calcium carbonate precipitation. PLOS ONE 6: e22338

Gutner-Hoch E, Waldman Ben-Asher H, Yam R, Shemesh A, Levy O. 2017. Identifying genes and regulatory pathways associated with the scleractinian coral calcification process. PeerJ 20: e3590

Hang TT, Kato K, Wada H. 2014. Magnetic separation of calcite and aragonite for use in radioactive carbon analysis: Geochemical journal 48: 113-119.

Hartwig A. 2001. Role of magnesium in genomic stability. Mutation Research 475:113-121.

Higuchi T, Fujimura H, Yuyama I, Harii S, Agostini S, Oomori T. 2014. Biotic control of skeletal growth by scleractinian corals in aragonite-calcite seas. PLOS ONE 9: e91021.

Higuchi T, Shirai K, Mezaki T, Yuyama I. 2017. Temperature dependence of aragonite and calcite skeleton formation by a scleractinian coral in low $m \mathrm{Mg} / \mathrm{Ca}$ seawater. Geology 45 : 1087-1090.

Huang DW, Sherman BT, Lempicki RA. 2009. Systematic and integrative analysis of large gene lists using DAVID Bioinformatics Resources. Nature Protoc 4: 44-57.

Iwao K, Fujisawa T, Hatta M. 2002. A cnidarian neuropeptide of the GLWamide family induces metamorphosis of reef-building corals in the genus Acropora. Coral Reefs 21: 127-129.

Janiszewska K, Mazur M, Escrig S, Meibom A, Stolarski J. 2017. Aragonitic scleractinian corals in the Cretaceous calcitic sea. Geology 45: 319-322.

Jiao Y, Wang H, Du X, Zhao X, Wang Q, Huang R, Deng Y. 2012. Dermatopontin, a shell matrix protein gene from pearl oyster Pinctada martensii, participates in nacre formation Biochem Biophys Res Commun 425: 679-683.

Katz JL, Reick MR, Herzog RE, Parsiegla KI (1993) Calcite Growth Inhibition by Ions. Langmuir 9: 1423-1430

Mass T, Putnam HM, Drake JL, Zelzion E, Gates RD, Bhattacharya D, Falkowski PG. 2016. Temporal and spatial expression patterns of biomineralization proteins during early development in the stony coral Pocillopora damicornis. Proc Biol Sci 283:1829.

Li M, Yuan Y, Chen Q, Me R, Gu Q, Yu Y, Sheng M, Ke B. 2016. Expression of Wnt/ $\beta$-Catenin Signaling Pathway and Its Regulatory Role in Type I Collagen with TGF- $\beta 1$ in Scleral Fibroblasts from an Experimentally Induced Myopia Guinea Pig Model. J Ophthalmol 2016: 5126560.

Porter SM. 2007. Seawater chemistry and early carbonate biomineralization. Science 316:1302.

PeerJ reviewing PDF | (2018:12:33364:2:0:REVIEW 14 May 2019) 
338

339

340

341

342

343

344

345

346

347

348

349

350

351

352

353

354

355

356

357

358

359

360

361

362

363

364

365

366

367

368

369

370

371

372

373

374

375

376

377

Porter SM. 2010. Calcite and aragonite seas and the de novo acquisition of carbonate skeletons. Geobiology 8: 256-277.

Rahman MA, Oomori T. 2009. In vitro regulation of $\mathrm{CaCO}_{3}$ crystal growth by the highly acidic proteins of calcitic sclerites in soft coral, Sinularia polydactyla. Connect Tissue Res 50: 285293.

Ramos-Silva P, Kaandorp J, Huisman L, Marie B, Zanella-Cléon I, Guichard N, Miller DJ, Marin F. 2013. The skeletal proteome of the coral Acropora millepora: the evolution of calcification by co-option and domain shuffling. Mol Biol Evol 30: 2099-2112.

Reyes-Bermudez A1, Lin Z, Hayward DC, Miller DJ, Ball EE. 2009. Differential expression of three galaxin-related genes during settlement and metamorphosis in the scleractinian coral Acropora millepora. BMC Evol Biol 9: 178.

Ries JB, Stanley SM, Hardie LA. 2006. Scleractinian corals produce calcite, and grow more slowly, in artificial Cretaceous seawater. Geology 34: 525-528.

Ries JB. 2010. Review: geological and experimental evidence for secular variation seawater $\mathrm{Mg} / \mathrm{Ca}$ (calcite-aragonite seas) and its effects on marine biological calcification. Biogeosciences 7: 2795-2849.

Sarashina I, Yamaguchi H, Haga T, Iijima M, Chiba S, Endo K. 2006. Molecular evolution and functionally important structures of molluscan Dermatopontin: implications for the origins of molluscan shell matrix proteins. J Mol Evol 62:307-318.

Shinzato C, Shoguchi E, Kawashima T, Hamada M, Hisata K, Tanaka M, Fujie M, Fujiwara M, Koyanagi R, Ikuta T, Fujiyama A, Miller DJ, Satoh N. 2011. Using the Acropora digitifera genome to understand coral responses to environmental change. Nature 476: 320-332.

Stanley SM, Hardie LA. 1998. Secular oscillations in carbonate mineralogy of reef-building and sediment-producing organisms driven by tectonically forced shifts in seawater chemistry. Palaeogeogr Palaeoclimatol Palaeoecol 144: 3-19.

Stanley GD Jr. 2003. The evolution of modern corals and their early history. Earth Sci Rev 60: 195-225.

Sun J, Nishiyama T, Shimizu K, Kadota K. 2013. TCC: an R package for comparing tag count data with robust normalization strategies. BMC Bioinformatics 14:219.

Takeuchi T, Yamada L, Shinzato C, Sawada H, Satoh N. 2016. Stepwise Evolution of Coral Biomineralization Revealed with Genome-Wide Proteomics and Transcriptomics. PLoS ONE 11: e0156424.

Tsukamoto D, Sarashina I, Kazuyoshi E. 2004. Structure and expression of an unusually acidic matrix protein of pearl oyster shells. Biochem Biophys Res Commun 320: 1175-1180.

Uriz MJ. 2006. Mineral spiculogenesis in sponges. Can J Zool 84: 322-356

Yuyama I, Higuchi T. 2014. Comparing the effects of symbiotic algae (Symbiodinium) clades C1 and D on early growth stages of Acropora tenuis. PLoS ONE 9: e98999.

Yuyama I, Ishikawa M., Nozawa M, Yoshida M, Ikeo K 2018. Transcriptomic changes with increasing algal symbiont reveal the detailed process underlying establishment of coral-algal symbiosis. Scientific Reports 8, 16802. 
378

379

380

381

382

383

384

385

386

387

388

389

390

391

392

393

394

395

396

397

398

399

400

401

402

403

404

405

406

407

408

409

410

411

412

413

414

415

416

417

418

419

420

Zoccola D, Ganot P, Bertucci A, Caminiti-Segonds N, Techer N, Voolstra CR, Aranda M, Tambutté E, Allemand D, Casey JR, Tambutté S. 2015. Bicarbonate transporters in corals point towards a key step in the evolution of cnidarian calcification. Scientific Reports 5: 9983. Zoccola D, Moya A, Béranger GE, Tambutté E, Allemand D, Carle GF, Tambutté S. 2009. Specific expression of BMP2/4 ortholog in biomineralizing tissues of corals and action on mouse BMP receptor. Mar Biotechnol 11: 260-269.

Zoccola D, Tambutté É., Kulhanek E, Puverel S, Scimeca JC, Allemand D, Tambutté S. 2004. Molecular cloning and localization of a PMCA P-type calcium ATPase from the coral Stylophora pistillata. Biochim. Biophys. Acta 1663: 117-126.

\section{Electronic supplementary material}

Supplementary Information are uploaded as Fig. S1-S10 and Table S1-S3.

The raw fastq files for the RNA-seq libraries were deposited at the DDBJ Sequence Read Archive (DRA) under accession number DRA007943.

\section{FIGURE LEGENDS}

Figure $1 \mathrm{X}$ ray diffraction (XRD) pattern of juvenile skeleton of Acropora tenuis and observation image after Meigen's stain. Aragonite indicated by purple stained regions. (a) $m \mathrm{Mg} / \mathrm{Ca}=5.2$. (b) $m \mathrm{Mg} / \mathrm{Ca}=0.5$. Scale bars are $0.5 \mathrm{~mm}$.

Figure 2 GO enrichment analysis of differentially expressed genes (DEGs) under normal and low$m \mathrm{Mg} / \mathrm{Ca}$ conditions. Vertical axis: GO terms; horizontal axis: enrichment score (-Log10 (p-value).

Figure 3 The top 50 most significantly up-regulated and down-regulated genes. Colors indicate the expression patterns of each gene (Z-score transformed FPKM values) between control and low-Mg conditions.

Figure S1. Heat map displaying gene expression levels of detected DEGs between control and lowmagnesium conditions. Colors indicate Z-score transformed FPKM values of genes annotated with GO term: signaling receptor activity (GO:0038023); yellow and blue highlights indicate higher and lower expression values, respectively.

Figure S2. Heat map displaying gene expression levels of detected DEGs between control and lowmagnesium condition. Colors indicate Z-score transformed FPKM values of genes annotated with GO term: response to endogenous stimulus (GO:0009719); yellow and blue highlights indicate higher and lower expression values, respectively.

Figure S3. Heat map displaying gene expression levels of detected DEGs between control and low magnesium conditions. Colors indicate Z-score transformed FPKM values of genes annotated with GO 
421

422

423

424

425

426

427

428

429

430

431

432

433

434

435

436

437

438

439

440

441

442

443

444

445

446

447

448

449

450

451

452

453

454

455

456

457

458

459

460

461

462

463

464

term: extracellular matrix (GO:0031012); yellow and blue highlights indicate higher and lower expression values, respectively.

Figure S4. Heat map displaying gene expression levels of detected DEGs between control and low magnesium conditions. Colors indicate Z-score transformed FPKM values of genes annotated with GO term: cell surface receptor signaling pathway (GO:0007166); yellow and blue highlights indicate higher and lower expression values, respectively.

Figure S5. Heat map displaying gene expression levels of detected DEGs between control and low magnesium conditions. Colors indicate Z-score transformed FPKM values of genes annotated with GO term: calcium ion binding (GO:0005509); yellow and blue highlights indicate higher and lower expression values, respectively.

Figure S6. Heat map displaying gene expression levels of detected DEGs between control and low magnesium conditions. Colors indicate Z-score transformed FPKM values of genes annotated with GO terms: tetrapyrrole binding (GO:0046906), regulation of tumor necrosis factor biosynthetic process (GO: 0042534 ), response to oxidative stress (GO:0006979), sterol metabolic process (GO:0016125), Notch signaling pathway (GO:0007219), and secondary alcohol metabolic process (GO:1902652); yellow and blue highlights indicate higher and lower expression values, respectively.

Figure S7. Heat map displaying gene expression levels of detected DEGs between control and low magnesium conditions. Colors indicate Z-score transformed FPKM value of genes annotated with GO terms: serine hydrolase activity (GO:0017171), regulation of tumor necrosis factor biosynthetic process GO:0042534), response to oxidative stress (GO: 0006979), and regulation of MAPK cascade (GO:0043408); yellow and blue highlights indicate higher and lower expression values, respectively.

Figure S8. Heat map displaying gene expression levels of detected DEGs between control and low magnesium conditions. Colors indicate Z-score transformed FPKM value of genes annotated with GO terms: positive regulation of nitrogen compound metabolic process (GO:0051173), necrotic cell death (GO:0070265), potassium ion transport (GO:0006813), and metalloendopeptidase activity (GO:0004222); yellow and blue highlights indicate higher and lower expression values, respectively.

Figure S9, Heat map displaying gene expression levels of detected DEGs between control and lowmagnesium condition. Colors indicate Z-score transformed FPKM value of genes annotated with GO terms: macrophage activation (GO:0042116), fibroblast growth factor-activated receptor activity (O:0005007), copper ion binding (GO:0005507), collagen metabolic process (GO:0032963), cAMP biosynthetic process (GO:0006171), collagen fibril organization (GO: 0030199), JAK-STAT cascade (GO:0007259), and DNA-dependent DNA replication (GO:0006261); yellow and blue highlights indicate higher and lower expression values, respectively.

Figure S10. Heat map displaying gene expression levels of detected DEGs between control and lowmagnesium conditions. Colors indicate Z-score transformed FPKM value of genes annotated with GO terms: ameboidal type cell migration (GO:0001667) and Wnt signaling pathway (GO: 0016055); yellow and blue highlights indicate higher and lower expression values, respectively. 
466 Table S1 Top 50 most significantly up-regulated (a) and down-regulated (b) genes, showing expression 467 pattern for each gene between control and low-Mg conditions (deepening intensity of color indicating 468 higher expression value). Estimated m-values ( $\log 2$ (low-Mg/control)), and p-values for detecting 469 differentially expressed genes from FPKM and annotation information (BLASTx results against NCBI 470 non redundant database and the e-value) also shown (e-value cutoffs $<1$ e-6).

471

472 Table S2 Up-regulated genes in low $\mathrm{Mg} / \mathrm{Ca}$ related to skeletal organic matrix of coral. Listed skeletal 473 organic matrix given in Ramos-Silva et al. (2013).

474

475 Table S3 Down-regulated genes in low $\mathrm{Mg} / \mathrm{Ca}$ related to skeletal organic matrix of coral. Listed skeletal 476 organic matrix given in Ramos-Silva et al. (2013). 


\section{Figure 1}

$\mathrm{X}$ ray diffraction pattern and Juvenile skeleton of Acropora tenuis (After Meigen's stain).

$\mathrm{X}$ ray diffraction (XRD) pattern of juvenile skeleton of Acropora tenuis and observation image after Meigen's stain. Aragonite indicated by purple stained regions. (a) $\mathrm{mMg} / \mathrm{Ca}=5.2$. (b) $\mathrm{mMg} / \mathrm{Ca}=0.5$. Scale bars are $0.5 \mathrm{~mm}$. 
(a)
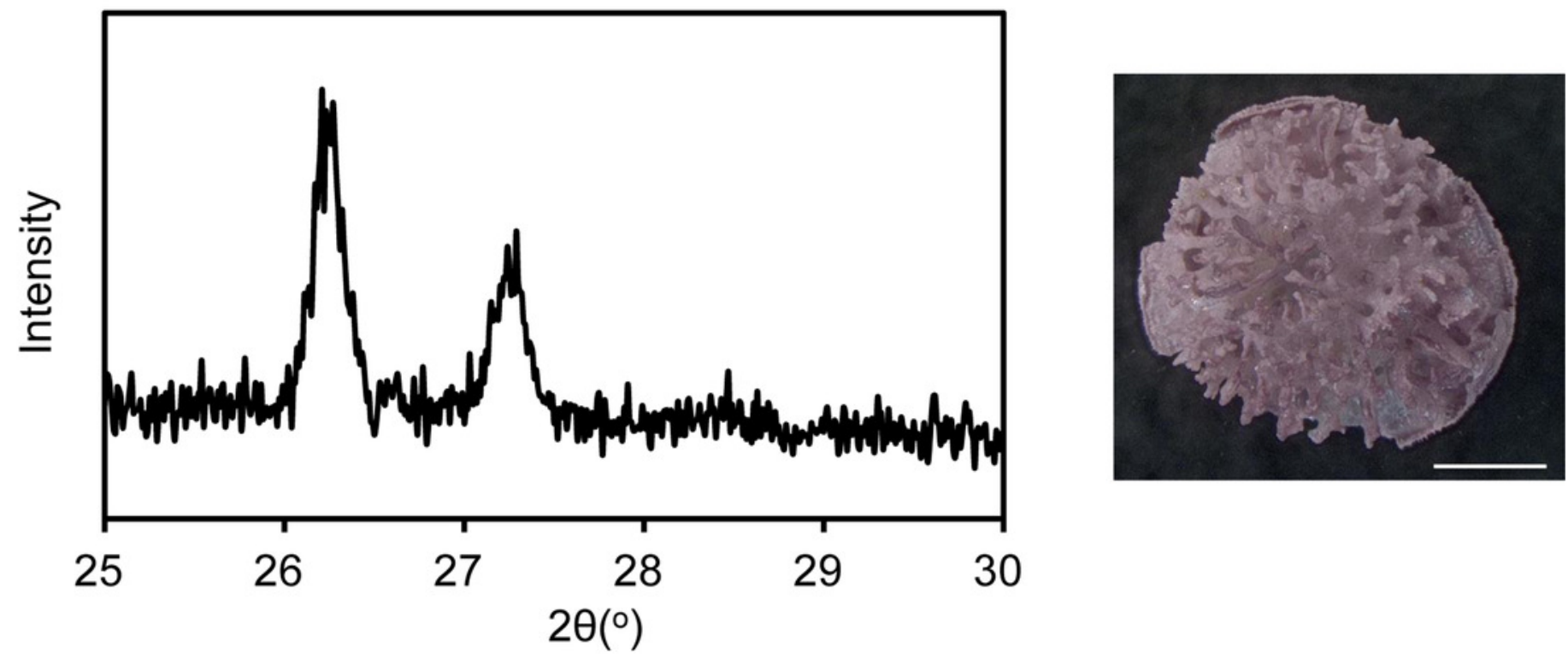

(b)
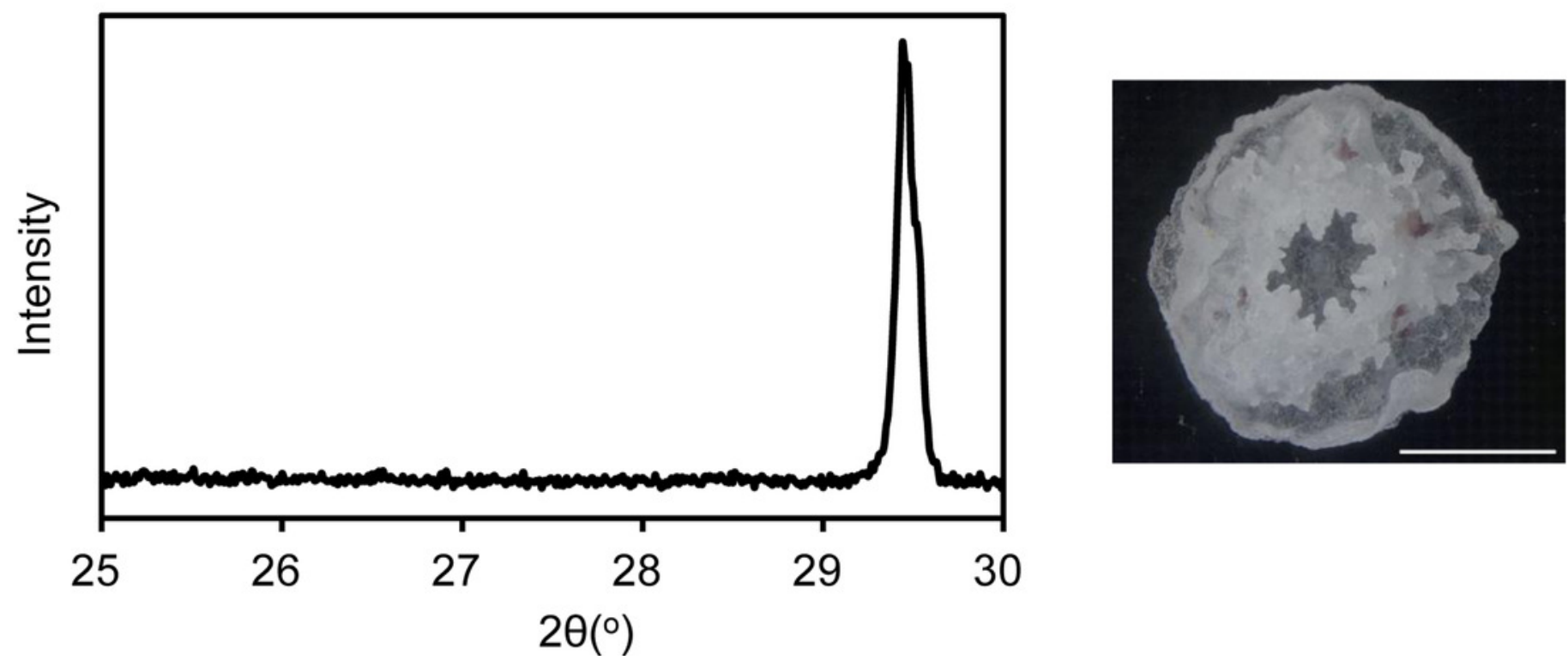
Figure 2

GO enrichment analysis of differentially expressed genes (DEGs) under normal and low$m \mathrm{Mg} / \mathrm{Ca}$ conditions.

GO enrichment analysis of differentially expressed genes (DEGs) under normal and low$\mathrm{mMg} / \mathrm{Ca}$ conditions. Vertical axis: GO terms; horizontal axis: enrichment score (-Log10 (pvalue). 


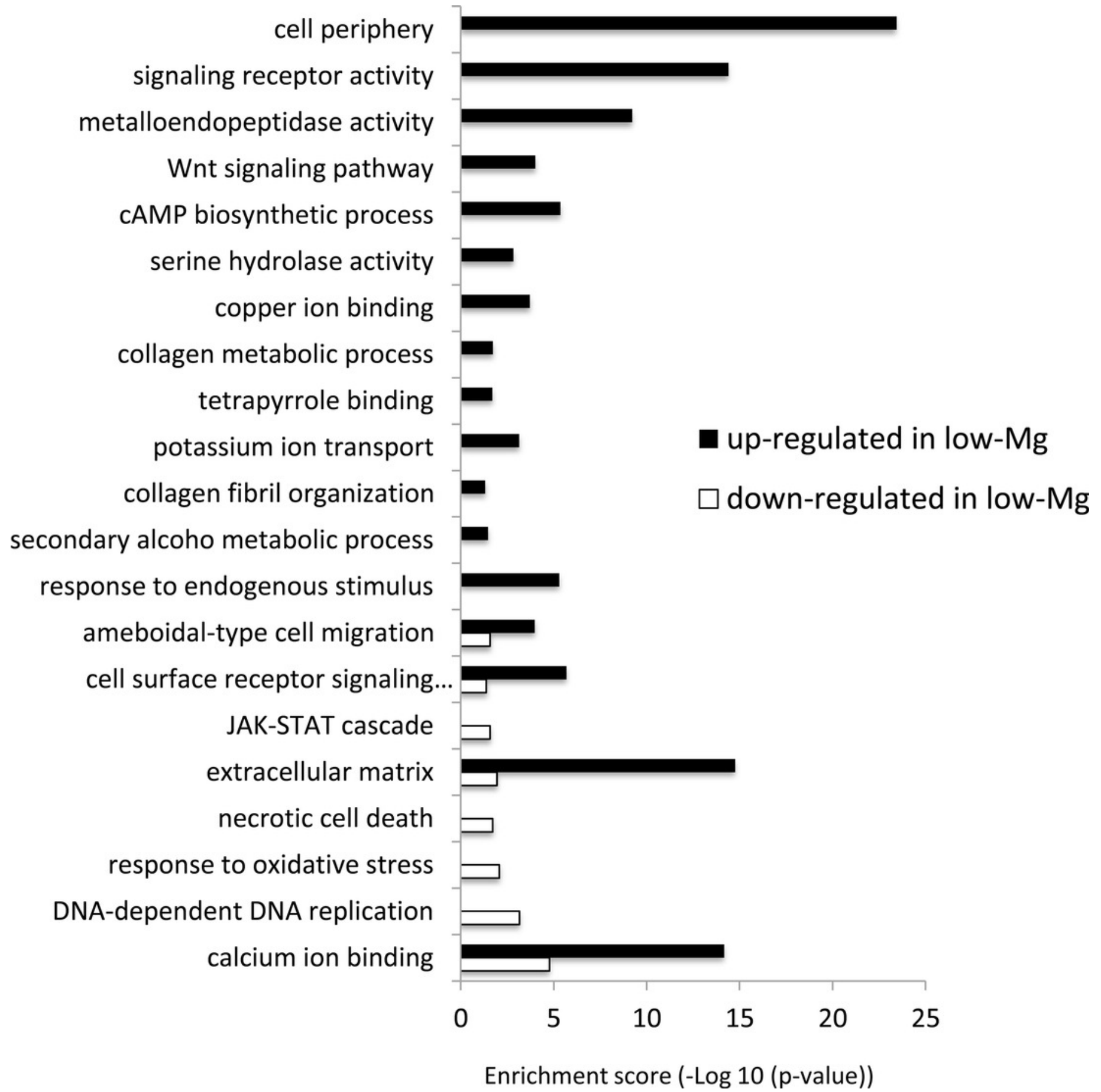


Figure 3

The top 50 most significantly up-regulated and down-regulated genes

The top 50 most significantly up-regulated and down-regulated genes. Colors indicate the expression patterns of each gene (Z-score transformed FPKM values) between control and low-Mg conditions. 


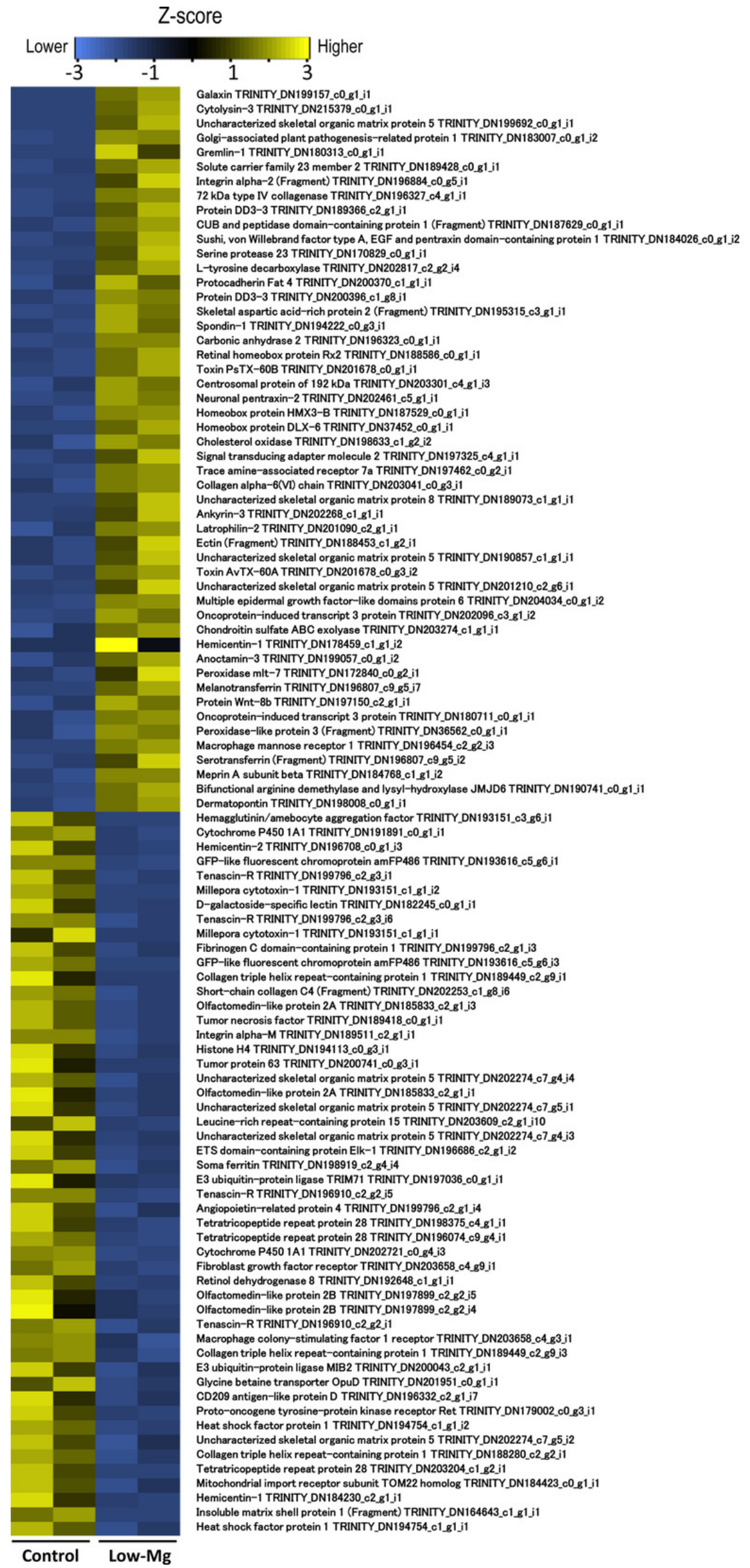

Peer) reviewing PDF | (2018:12:33364:2:0:REVIEW 14 May 2019) 